\title{
Synthesis and characterization of (Ti1- XAlx)B2+Delta thin films from combinatorial magnetron sputtering
}

Aurelija Mockuté, J ustinas Palisaitis, Nils Nedfors, P. Berastegui, Esteban Broitman, Björn Alling, Lars-Åke Näslund, Lars Hultman, J . Patscheider, U. J ansson, Per O A Persson and J ohanna Rosén

The self-archived postprint version of this journal article is available at Linköping University Institutional Repository (DiVA):

http:/ / urn.kb.se/ resolve?urn=urn:nbn:se:liu:diva-153652

N.B.: When citing this work, cite the original publication.

Mockuté, A., Palisaitis, J ., Nedfors, N., Berastegui, P., Broitman, E., Alling, B., Näslund, L., Hultman, L., Patscheider, J., J ansson, U., Persson, P. O A, Rosén, J ., (2019), Synthesis and characterization of (Ti1-xAlx)B2+Delta thin films from combinatorial magnetron sputtering, Thin Solid Films, 669, $181-$ 187. https:// doi.org/ 10.1016/j.tsf.2018.10.042

Original publication available at:

https:/ / doi.org/ 10.1016/j.tsf.2018.10.042

Copyright: Elsevier

http:// www.elsevier.com/

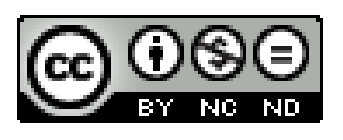




\title{
Synthesis and characterization of $\left(\operatorname{Ti}_{1-x} \mathrm{Al}_{x}\right) \mathrm{B}_{2+\Delta}$ thin films from combinatorial magnetron sputtering
}

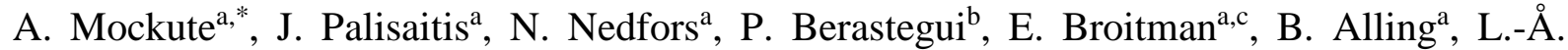 \\ Näslund $^{\mathrm{a}}$, L. Hultman ${ }^{\mathrm{a}}$, J. Patscheider ${ }^{\mathrm{d}}$, U. Jansson ${ }^{\mathrm{b}}$, P.O.Å. Persson ${ }^{\mathrm{a}}$, J. Rosen ${ }^{\mathrm{a}}$ \\ ${ }^{a}$ Thin Film Physics Division, Department of Physics, Chemistry, and Biology (IFM), Linköping \\ University, SE-58183 Linköping, Sweden \\ ${ }^{b}$ Department of Materials Chemistry, Ångström Laboratory, Uppsala University, P.O. Box 583, \\ SE-75121 Uppsala, Sweden \\ 'SKF Research and Technology Development Center, 3439 MT Nieuwegein, Netherlands \\ ${ }^{d}$ Evatec AG, Hauptstrasse 1a, CH-9477 Trübbach, Switzerland
}

*Corresponding author; tel.: +4613281279, e-mail address: aurmo@ifm.liu.se

\begin{abstract}
$\left(\mathrm{Ti}_{1-x} \mathrm{Al}_{x}\right) \mathrm{B}_{2+\Delta}$ films with a lateral composition gradient of $x=[0.30-0.66]$ and $\Delta=[0.07-$ 1.22] were deposited on an $\mathrm{Al}_{2} \mathrm{O}_{3}$ wafer by dual magnetron sputtering at $400{ }^{\circ} \mathrm{C}$ from sintered $\mathrm{TiB}_{2}$ and $\mathrm{AlB}_{2}$ targets. Composition analysis indicates that higher $\mathrm{Ti}$ :Al ratios favor overstoichiometry in $\mathrm{B}$ and a reduced incorporation of $\mathrm{O}$. Transmission electron microscopy reveals distinctly different microstructures of $\mathrm{Ti}$ - and Al-rich compositions, with formation of characteristic conical growth features for the latter along with a lower degree of crystallinity and significantly less tissue phase from B segregation at the grain boundaries. For Al-rich films, phase separation into $\mathrm{Ti}$ - and Al-rich diboride nanometer-size domains is observed and interpreted as surface-initiated spinodal decomposition. The hardness of the films ranges from 14 to $28 \mathrm{GPa}$, where the higher values were obtained for the Ti-rich regions of the metal boride.
\end{abstract}

Keywords: titanium aluminium diboride, thin films, combinatorial sputtering, mechanical properties, phase decomposition

\section{Introduction}

Titanium diboride $\left(\mathrm{TiB}_{2}\right)$ is an extremely hard ceramic material, particularly well-studied in bulk form, which has excellent thermal and electrical conductivity, high melting point, chemical stability, and resistance to mechanical erosion [1]. $\mathrm{TiB}_{2}$ crystallizes in a hexagonal $\mathrm{AlB}_{2}$-type structure, where hexagonal-close-packed $\mathrm{Ti}(0001)$ planes are interleaved by layers of interstitial $\mathrm{B}$ atoms. Non-reactive magnetron sputtering has been the primary technique for synthesis of thin films of $\mathrm{TiB}_{2}$, see, e.g., Ref. [2-6], where overstoichiometric (0001) textured films with nanocolumnar microstructure and compressive residual stress have typically been observed [3, $4,7,8]$. The excess B segregates to grain boundaries forming an amorphous B tissue phase [4], which together with the nanocolumnar microstructure results in superhard coatings with hardness values up to $\sim 60 \mathrm{GPa}$ [4]. $\mathrm{TiB}_{2}$ coatings pose a high potential for improved performance in various tribological applications, e.g., reduced wear and corrosion, or as protective coatings for cutting tools. However, common industrial substrates, such as most steels, have a considerably lower elastic modulus ( $200 \mathrm{GPa}$ [9]) than $\mathrm{TiB}_{2}$ ( $\sim 60 \mathrm{GPa}$ [9]), which, combined with high thermally induced stress, negatively affects the $\mathrm{TiB}_{2}$ coating adhesion and results in early failure. In general, materials performance may be improved by synthesis of multicomponent systems, which allows tuning of the properties and control of the microstructure, resulting in overall enhanced functionality [10,11]. Various ternary systems of 
transition metal diborides are explored in order to obtain superior properties, e.g., $\mathrm{W}_{1-x} \mathrm{Ta}_{x} \mathrm{~B}_{2-z}$ for a combination of both mechanical strength and ductility $[12,13]$. An example for hardcoating applications is $\mathrm{Ti}_{1-x} \mathrm{Al}_{x} \mathrm{~N}$, where $\mathrm{Ti}$ in $\mathrm{TiN}$ is partially replaced by $\mathrm{Al}$, leading to age hardening effect through isostructural clustering, a primary reason behind its success [14]. Alloying $\mathrm{TiB}_{2}$ with $\mathrm{Al}$ reduces elastic modulus to about $325 \mathrm{GPa}$ for low-temperature synthesis of Ti-Al-B coatings, co-deposited from $\mathrm{TiAl}$ and $\mathrm{TiB}_{2}$ targets $[15,16]$, and with an $\mathrm{Al}$ content of $<10$ at. \% (i.e., composition close to $\mathrm{TiB}_{2}$ ), thus providing a significantly better elastic moduli match between the coating and the application-relevant substrate. Furthermore, most recent theoretical calculations indicate coherent isostructural decomposition of $(\mathrm{Ti}, \mathrm{Al}) \mathrm{B}_{2+4}$ with a strong driving force for phase separation [17] potentially increasing the hardness. Deposition and subsequent heat treatment of corresponding thin films resulted in improved mechanical properties in terms of hardness and elastic modulus [18]. It is thus important to systematically map out the composition-structure window for the Ti-Al-B system. In this study, a combinatorial approach is employed to examine the dependence of microstructure and mechanical properties in terms of elastic modulus and hardness on the composition of magnetron sputtered $\left(\mathrm{Ti}_{1-x} \mathrm{Al}_{x}\right) \mathrm{B}_{2+\Delta}$ thin films. Emphasis is also put on investigating the correlation between degree of overstoichiomery and the Ti:Al ratio.

\section{Experimental Details}

Combinatorial deposition of Ti-Al-B on a 3" diameter $\mathrm{Al}_{2} \mathrm{O}_{3}(0001)$ wafer was performed by non-reactive dual dc magnetron sputtering using 3" sintered $\mathrm{TiB}_{2}$ (99.5\% purity) and $\mathrm{AlB}_{2}$ (99.9 \% purity) targets, each positioned at an angle of $39^{\circ}$ from the substrate normal, with an orthogonal distance of $15 \mathrm{~cm}$. Sapphire substrate was chosen due to a good lattice match and good film adherence. Prior to deposition the substrate was degassed in the vacuum chamber at the growth temperature of $400{ }^{\circ} \mathrm{C}$ for $30 \mathrm{~min}$. The vacuum chamber, which had a base pressure of $4.5 \cdot 10^{-6} \mathrm{~Pa}$, was fed with $10.4 \mathrm{sccm}$ Ar introduced up to a partial pressure of $1.3 \cdot 10^{-1} \mathrm{~Pa}$. The deposition was carried out for $2 \mathrm{~h}$ in power-controlled mode with $100 \mathrm{~W}\left(2.19 \mathrm{~W} / \mathrm{cm}^{2}\right)$ on the $\mathrm{TiB}_{2}$ and $100 \mathrm{~W}\left(2.19 \mathrm{~W} / \mathrm{cm}^{2}\right)$ on the $\mathrm{AlB}_{2}$ targets, and with a substrate bias of $-50 \mathrm{~V}$. The wafer orientation with respect to the targets is shown in the inset in Fig. 1. Hereafter, the wafer areas closer to the $\mathrm{TiB}_{2}$ target and the $\mathrm{AlB}_{2}$ target are referred to as the $\mathrm{TiB}_{2}$-side and the $\mathrm{AlB}_{2}$ side, respectively. The layers were grown to a thickness of 200 to $250 \mathrm{~nm}$.

The structural properties of the films were investigated by X-ray diffraction (XRD) using a Panalytical Empyrean MRD system equipped with a $\mathrm{Cu} K \alpha$ source $(\lambda=1.54 \AA)$. Symmetric $\theta$ $2 \theta$ scans were performed with $\mathrm{X}$-rays in point focus using a hybrid mirror optics on the incident side and an X-ray lens on the diffracted side. The diffractograms were acquired in a 5 x 5 array (see inset in Fig. 1) with a distance of $13.5 \mathrm{~mm}$ between each spot.

The nanoindentation hardness $(\mathrm{H})$ and reduced Young's modulus $\left(\mathrm{E}_{\mathrm{r}}\right)$ were investigated by a Triboindenter TI950 instrument from Hysitron. The nanoindentations were conducted with a Berkovich diamond probe, which has been calibrated prior to the analysis using a fused silica reference. $\mathrm{H}$ and $\mathrm{E}_{\mathrm{r}}$ were calculated by the method of Oliver and Pharr using the unloading elastic part of the load-displacement curve [19]. A mapping of the mechanical properties was performed by recording loading-unloading curves in load-controlled mode at 25 different area spots arranged in a $5 \times 5 \mathrm{~cm}^{2}$ grid, corresponding to the same positions as for the XRD measurements. An array of twelve indents separated by $10 \mu \mathrm{m}$ and with a penetration depth of $50 \mathrm{~nm}$ was recorded at each area spot, the mean value and the standard deviation of $\mathrm{H}$ and $\mathrm{E}_{\mathrm{r}}$ for these 12 indents in each area is reported. The maps were generated by the software Origin Pro 8.5 using an increase factor of 200 points and a smoothing parameter of 0.1 . In a recent 
paper, the influence of the substrate on the measured film mechanical properties has been discussed [20]. The work shows how Buckle's rule of the $10 \%$ film-thickness indentation depth limit is not valid all the time. That rule is not stringent enough for hard coatings on a very soft substrate, and inversely, the rule is too strict for coatings on a harder substrate. As it is discussed by Broitman [20], in our case the low tip penetration, in combination with the supporting sapphire substrate (hardness $30 \mathrm{GPa}$ [21]), assures that the substrate does not influence the measured $\mathrm{H}$ and $\mathrm{E}_{\mathrm{r}}$ values.

Elemental composition was determined using a Kratos Analytical Ultra ${ }^{\text {DLD }}$ X-ray photoelectron spectroscopy (XPS) system with monochromatic Al Ka radiation. The measurements were performed at selected positions on the $5 \mathrm{x} 5$ grid (see schematics in Table 1) along the expected composition gradient through the wafer center as well as along a parallel line on either side. Prior to analysis, $3 \times 3 \mathrm{~mm}^{2}$ surface area was sputter-etched for 3 min using $500 \mathrm{eV} \mathrm{Ar}^{+}$ions at an incident beam angle of $25^{\circ}$ relative to the surface plane. Quantification was performed after the background contributions were removed using a Shirley function. The difference in the photoemission cross-section was compensated through relative sensitivity factors obtained from the Vision Processing software package provided by Kratos Analytical. The relative sensitivity factors used were 2.001 for Ti 2p, 0.193 for Al 2p, 0.159 for B 1s, 0.780 for O 1s, 0.278 for $\mathrm{C} 1 \mathrm{~s}$, and 0.477 for $\mathrm{N} 1 \mathrm{~s}$.

Samples for transmission electron microscopy (TEM) analysis were obtained from the wafer at positions $\mathrm{D}$ and $\mathrm{H}$ along the Ti-Al gradient. Plan-view TEM samples were prepared by focused ion beam (FIB) technique employing a Carl Zeiss Cross-Beam 1540 EsB system following a procedure described elsewhere [20]. Cross-sectional TEM samples were prepared by the traditional "sandwich" approach which includes sample cutting, gluing, and polishing followed by $\mathrm{Ar}^{+}$ion milling at $5 \mathrm{keV}$ and $5^{\circ}$ angle from both sides in a Gatan precision ion polishing system (PIPS). A final low energy milling step was applied at $2 \mathrm{keV}$ in order to reduce the surface damage. Scanning TEM high angle annular dark field (STEM-HAADF) imaging, STEM energy-dispersive X-ray spectroscopy (STEM-EDX), and STEM electron energy-loss spectroscopy (STEM-EELS) were performed using the double-corrected Linköping FEI Titan ${ }^{3}$ 60-300, operated at $300 \mathrm{kV}$. High-resolution STEM-HAADF images were acquired by using a 21.5 mrad probe convergence angle for sub-Ångstrom imaging with $\sim 80$ pA current. STEMEDX and STEM-EELS spectrum imaging (SI) were performed using $\sim 0.3 \mathrm{nA}$ beam current. STEM-EDX spectrum images of 252 x 252 pixels were acquired for 3 min employing the high sensitivity Super-X EDX detector. STEM-EELS spectrum images of 50 x 50 pixels were acquired for $5 \mathrm{~min}$ using a $0.25 \mathrm{eV} /$ channel energy dispersion, $0.2 \mathrm{~s}$ dwell time for each pixel and employing a Gatan GIF Quantum ERS post-column imaging filter [22].

\section{Results and Discussion}

Figure 1 shows XRD $\theta-2 \theta$ scans acquired at different spots on the wafer. In all scans peaks at $\sim 27.3^{\circ}$ and $56.3^{\circ}$ are present, which can be attributed to the (0001) and (0002) planes of the expected $\mathrm{AlB}_{2}$-type crystal structure [23]. The incident X-ray beam has not been filtered entirely from the $\mathrm{Cu} \mathrm{K} \beta$ radiation, and thus the $\beta$ peak from the $\mathrm{Al}_{2} \mathrm{O}_{3}$ substrate is also present at $37.6^{\circ}$. The inset in Fig. 1 shows a close-up on the (0001) film peak. The scans fall in five distinct groups (five scans in each), depending on distance to the targets. For these groups, the (0001) peak position shifts from $27.26^{\circ}$ to $27.48^{\circ}\left(\Delta 2 \theta=+0.22^{\circ}\right)$ as well as the intensity is reduced by $60 \%$ from the initial value when measured from the $\mathrm{AlB}_{2}$-side to $\mathrm{TiB}_{2}$-side of the wafer along the expected Al-Ti composition gradient. The previously reported (0001) peak positions for isostructural $\mathrm{AlB}_{2}$ and $\mathrm{TiB}_{2}$ phases are at $27.30^{\circ}$ [24] and $27.54^{\circ}$ [4], respectively. 
No peak shift or intensity change is observed in between the measurements performed in the direction perpendicular to the plane intersecting the two targets.

Table 1 presents elemental composition and corresponding stoichiometry determined by XPS at selected positions on the wafer. The Ti:Al ratio changes uniformly from 0.70:0.30 on the $\mathrm{TiB}_{2}$-side to $0.35: 0.65$ on the $\mathrm{AlB}_{2}$-side. The Ti:Al ratio at the wafer center is 0.53:0.47, which is close to the expected 0.50:0.50 ratio based on equal powers applied to the $\mathrm{TiB}_{2}$ and $\mathrm{AlB}_{2}$ targets in combination with similar $\mathrm{TiB}_{2}$ and $\mathrm{AlB}_{2}$ growth rates. The Ti:Al ratio is constant perpendicular to the line joining $\mathrm{TiB}_{2}$ - and $\mathrm{AlB}_{2}$-sides. The $\mathrm{B}$ content, although overall overstoichiometric, tends to be slightly higher on the right side of the wafer. This effect could be explained by an asymmetric experimental setup with minor unintentional sputtering from an unused B target mounted closer to the right side of the wafer. Higher accommodation of B is obtained for higher Ti:Al ratios. This is consistent with the previously established overstoichiometry in magnetron sputtered $\mathrm{TiB}_{2}$ thin films [25, 26]. On the other hand, lower $\mathrm{Ti}$ :Al ratio, i.e., more $\mathrm{Al}$, correlates with an increased incorporation of $\mathrm{O}$. It can, to the most part, be ascribed to post-deposition $\mathrm{O}$ incorporation, evident from $\mathrm{O}$ primarily located along the grain boundaries as revealed in Fig. 2e.

The chemical evolution of the $\mathrm{B} / \mathrm{Ti}$ ratio on the wafer can be attributed to a combination of different kinetic energy of the atoms emitted from the target and their angular distribution. This, in turn, may be influenced by gas-phase scattering, where Ti has a shorter mean-free-path compared to B at the same pressure, based on mass and radius of the colliding atoms [26]. An increase in pressure and/or distance, as well as an increase in off-axis angle used for deposition, has previously been shown to reduce the B/Ti ratio, at least in part, explained by gas-phase scattering [26]. Furthermore, it has been suggested that use of a high bias for deposition of a metal boride can cause preferential resputtering of B [27], to what extent depending on sputtering angle, ion kinetic energy, etc. Hence, resputtering also needs to be considered for evaluation of the wafer composition.

The deviation from chemical purity and exact diboride stoichiometry in our samples motivates that the comparison with the theoretical results of Alling et al. [17] is made with some care. However, as we conclude that the main part of the overstoichiometry in B is accommodated in the tissue phase, the local composition in the $\mathrm{AlB}_{2}$-structure phase is closer to the ideal case than what would be assumed from the total global composition. Therefore, a comparison of the present findings with the prediction of Alling et al. [17] is still valuable.

A detailed STEM study was performed for the Ti-Al-B films obtained from wafer positions D and $\mathrm{H}$, corresponding to Ti- and $\mathrm{Al}$-rich specimens of $\left(\mathrm{Ti}_{0.70} \mathrm{Al}_{0.30}\right) \mathrm{B}_{3.22}$ and $\left(\mathrm{Ti}_{0.34} \mathrm{Al}_{0.66}\right) \mathrm{B}_{2.07}$. The Al-rich composition was chosen motivated by the theoretically predicted maximum mixing enthalpy (i.e., strongest driving force for phase separation) for $x=0.625$ [17], with the opposite $\mathrm{Ti}$ :Al ratio chosen for reference.

Figures 2a and $b$ show the STEM-HAADF images from the Al-rich $\left(\operatorname{Ti}_{0.34} \mathrm{Al}_{0.66}\right) \mathrm{B}_{2.07}$ film, in plan-view and cross section, respectively, revealing a dense columnar structure. The $\sim 230 \mathrm{~nm}$ thick film exhibits conical columns, emerging at the interface to the substrate and competing for growth along the substrate normal direction with an internal fine structure that is crystallographically aligned along [0001]. Cross-sectional STEM-HAADF images (Fig. 2b) revealed pronounced bright line at the substrate/film interface which was attributed to the enhanced Ti content at the beginning of the film growth which was confirmed by EDX analysis (not shown). Also, cross-sectional HRTEM showed that very first atomic layers of grown 
material exhibit an amorphous nature meaning that no considerable strain is introduced through lattice mismatch (not shown).

The majority of the columns exhibit a rounded surface truncation and homogenous STEMHAADF contrast with a column width in the range of 20-30 nm (Fig. 2a), which run parallel to the film growth direction with constant width throughout the film (Fig. 2b). However, a significant number of larger column-like features, locally increasing the film roughness, was observed in plan-view exhibiting elliptic shapes with widths in the range of 50-80 nm (Fig. 2a). Cross-sectional imaging revealed that these column-like features observed in plan-view relate to columns of conical shape with their width gradually increasing throughout the thickness of the film.

Interestingly, the conical-growth features exhibit partitioning of $\mathrm{Al}$ and $\mathrm{Ti}$, as revealed from atomic number sensitive STEM-HAADF imaging and STEM-EDX elemental mapping as shown in Fig. 2c-e. The STEM-HAADF images display darker and brighter contrast in areas that correspond to enrichment in $\mathrm{Al}$ and $\mathrm{Ti}$, respectively. From the elemental maps it is also apparent that tissue phase enclosing the conical defects enriched in oxygen. Al-rich and Ti-rich parts are asymmetric, where the Al-rich one is always smaller in volume which is most likely related to self-shadowing effects of the opposite incoming $\mathrm{Ti}$ and $\mathrm{Al}$ fluxes, given the surface height modulation of the emerging cones. STEM-EELS elemental mapping further revealed the boron and oxygen distribution in the conical defects, where $\mathrm{B}$ is found to peak at the edge of the Al-rich Ti-Al-B part and is significantly reduced in the adjacent areas that instead are enriched in oxygen. Larger area STEM-EELS maps revealed the slight enrichment of B at grain boundaries, which are considered as amorphous tissue phase, while for more pronounced boundaries between columns a significant amount of $\mathrm{O}$ is observed (see Fig. 3). Backgroundsubtracted and deconvoluted core-loss EELS spectra displaying strong B-K absorption edges and their characteristic shapes obtained from indicated regions of the Al-rich $\left(\operatorname{Ti}_{0.34} \mathrm{Al}_{0.66}\right) \mathrm{B}_{2.07}$ film are shown in Fig. 4. The individual spectra were extracted from the EELS map (Fig. 3). and vertically shifted with respect to each other. The spectra reveal significant differences in the fine structures suggesting different B chemical environments. The overall B edge fine structure contains a shoulder at $\sim 190 \mathrm{eV}$ and two apparent features at $\sim 195 \mathrm{eV}$ and $\sim 204 \mathrm{eV}$ energy loss. The most pronounced features at $\sim 195 \mathrm{eV}$ were observed for B edge obtained from at the tissue phase enclosing the conical defect (spectrum "1" in Fig. 4), which is also enriched in oxygen (Fig. 3e). Previously such sharp features were matched and attributed as the signature of $\mathrm{B}-\mathrm{O}$ bonding in $\mathrm{MoB}_{2-x}$ film tissue phase [28].

Plan-view high-resolution STEM-HAADF images acquired from a conical growth feature and corresponding fast Fourier transform (FFT) patterns show that the Ti- and Al-rich counterparts exhibit the same crystallographic nature and identical relationship to the substrate. A $c$-axis fiber texture is, however, present as reflected in the selected area electron diffraction (SAED) pattern with arch-like single-crystal diffraction peaks shown in the insets of Fig. 2a-b, consistent with XRD results. The fiber texture is interpreted here as semi-coherent domains evolving in a fan-like manner from [0001].

According to Alling et al. [17], the driving force for phase separation is highest at $x=$ 0.625 , which is close to our analyzed samples with $x=0.66$. The STEM-EDX finding in Fig. 2c-e about the formation of Ti- and Al-rich diboride domains can thus be interpreted as phase separation during film deposition of supersaturated $(\mathrm{Ti}, \mathrm{Al}) \mathrm{B}_{2}$ solid-solutions. The different domains should form semi-coherent interfaces by virtue of the difference in lattice parameter as a function of metal ratio. The phase separation is, however, not complete and would exclude 
a nucleation and growth process for $\mathrm{TiB}_{2}$ and $\mathrm{AlB}_{2}$, since no splitting of the (0001) peak parallel to the film surface is present (c f. Fig. 1). The observed transformation can be better interpreted as spinodal decomposition towards $\mathrm{TiB}_{2}$ and $\mathrm{AlB}_{2}$. The process is surface-initiated, because the partitioning of elements would experience less diffusion barrier in comparison to bulk, as reported for the TiAlN thin film system [29]. Thus, the composition gradient would be strongest across planes most inclined to the surface, which, however, could not be sampled with the present $\theta-2 \theta$ scans due to the exclusive crystallographic texture. Future investigations should probe the $\{10-10\}$ and $\{11-20\}$ planes for peak broadening and/or shoulder formation effects.

We propose that the different diboride domains evolve in the observed fan-like manner because of the lattice misfit dislocation formation in combination with concurrent local B segregation to the growth surface, that hinders coherent growth of either phase. A corresponding microstructure evolution was reported for the TiSiN thin film system [30]. This growth mode is most characteristic for our high-Al-content diboride films, as the Ti-rich films exhibit weaker metal segregation, as expected from the theoretical predictions [17].

Figure 5 shows STEM-HAADF images from Ti-rich $\left(\operatorname{Ti}_{0.70} \mathrm{Al}_{0.30}\right) \mathrm{B}_{3.22}$ revealing a dense columnar structure of the film and the film thickness of around $240 \mathrm{~nm}$. The grains in planview projection are preferentially elongated along the [1-100] direction with their characteristic width of 10-20 nm perpendicular to the grain elongation and 40-50 nm parallel. In cross-section the film exhibits a dense columnar microstructure, where the grains are inclined $\sim 20^{\circ}$ with respect to the surface normal (in [11-20]) (see Fig. 5b), which accounts for plan-view observations of grain elongation.

We have observed a deviation of the lattice plane orientation from the ideal $c$-axis orientation towards the film surface (see Fig. $5 c-d$ ). The $c$-axis of the same grain is deviating by $\sim 5^{\circ}$ from its ideal [0001] orientation close to the film surface as compared to the film-substrate interface. SAED patterns shown in the insets of Fig. 5 reveal the fiber texture of the grown film with $c$ axis preferential growth orientation, which starts to deviate towards the film surface. $\left(\mathrm{Ti}_{0.70} \mathrm{Al}_{0.30}\right) \mathrm{B}_{3.22}$ contains conical domains similar in nature to ones observed in $\left(\mathrm{Ti}_{0.34} \mathrm{Al}_{0.66}\right) \mathrm{B}_{2.07}$. However, the density of such domains is low; only one conical domain was observed in plan-view, where the Al-rich counterpart was significantly smaller in volume compared to the Ti-rich one. STEM-EDX/EELS mapping revealed that $\mathrm{Ti}$ and $\mathrm{Al}$ are homogenously distributed within the grains while the grain boundaries are B-enriched which is attributed to the formation of a $\mathrm{B}$ tissue phase. No preferential $\mathrm{O}$ incorporation in the tissue phase was observed in this case.

These observations point towards challenges of producing stoichiometric, single-phase high structural quality $\left(\mathrm{Ti}_{1-x} \mathrm{Al}_{x}\right) \mathrm{B}_{2}$ films without a tissue phase during sputtering from diboride targets. Despite the very close to ideal B:metal ratio of 2:1 in position $\mathrm{H}$, the relatively high $\mathrm{Al}$ content promotes formation of the conical domains. On the other hand, increasing the Ti content tends to result in B excess.

Figures 6a and b present hardness and reduced elastic modulus maps, respectively. A continuous hardness increase from $14 \mathrm{GPa}$ closest to the $\mathrm{AlB}_{2}$ target to $28 \mathrm{GPa}$ at the $\mathrm{TiB}_{2}$-side is observed, although the increase is more pronounced on the left side of the wafer. A similar behavior is observed for the reduced elastic modulus, which is increasing from 106 GPa to 278 $\mathrm{GPa}$ when going from the side closest to the $\mathrm{AlB}_{2}$ target to the $\mathrm{TiB}_{2}$-side. It has been shown, that $\mathrm{AlB}_{2}$ exhibits lower hardness and reduced elastic modulus compared to $\mathrm{TiB}_{2}$ in thin film 
form [4, 9, 31] as well as in ab initio calculations for bulk crystals [32], and thus the observed decrease in the values correlates with a decreasing Ti:Al ratio.

Mechanical properties are also affected by formation of conical domains, along with a varying width of the tissue phase in between the grains. A large disparity is seen between the left and right side of the wafer with higher elastic modulus values for the latter side, which might be related to the more pronounced $B$ excess and would thus have an effect on the film microstructure.

Figures 6c and d present standard deviation of the measured hardness and reduced elastic modulus values, respectively. The $\mathrm{H}$ data dispersion is small in all areas at the upper part of the wafer, i.e., up to $x=0.5$, while the data is increasingly more dispersed with higher Al content. Larger $\mathrm{H}$ data dispersion in each analyzed area most likely originates from the formation of conical domains observed in TEM (Fig. 2 and 3). These surface defects are randomly distributed and will affect the $\mathrm{H}$ values according to the number of cones that are affected in one indentation. On the other hand, the $\mathrm{E}_{\mathrm{r}}$ dispersion is less than $7 \%$ in areas where $\mathrm{H}$ dispersion climbs to $17 \%$. The elastic modulus represents the elastic behavior of the material calculated from the unloading part of the load-displacement nanoindentation curve (after the plastic deformation took place), and therefore is not affected by the plastic deformation of the cones. Thus, $\mathrm{H}$ dispersion on nanoindentation data can be used in our case to visualize the inhomogeneities of the microstructure (Fig. 6c). It also indicates that formation of the domains is promoted as soon as the $\mathrm{Al}$ content is higher than Ti, i.e., $x>0.5$.

It is well known that surface roughness influences nanoindentation data [20,33]. Evidently, the formation of the cones increases the roughness in some areas of our sample, but we can dismiss the possibility that the measured high dispersion on $\mathrm{H}$ is produced only by an increase of roughness: in that case, both $\mathrm{H}$ and $\mathrm{E}_{\mathrm{r}}$ should be affected in a similar way (see [33] and references therein).

\section{Conclusions}

We have performed combinatorial thin film synthesis of $\left(\mathrm{Ti}_{1-x} \mathrm{Al}_{x}\right) \mathrm{B}_{2+\Delta}$ with $x=[0.3-0.66]$ and $\Delta=[0.07-1.22]$ using dual magnetron sputtering. Structural and compositional analyses show columnar microstructure with conical features for the Al-rich compositions. Surfaceinitiated spinodal decomposition towards $\mathrm{TiB}_{2}$ and $\mathrm{AlB}_{2}$ nanometer-size semicoherent domains is demonstrated for Al-rich diboride compositions. Ti-rich films, however, exhibit no metal segregations in line with recent theoretical predictions of lower driving force for separation of those compositions of the pseudo-binary alloys. A hardness increase from $14 \mathrm{GPa}$ to $28 \mathrm{GPa}$ is observed with increasing $\mathrm{Ti}$ to $\mathrm{Al}$ ratio. Apart from a known higher hardness of $\mathrm{TiB}_{2}$ compared to $\mathrm{AlB}_{2}$, the mechanical properties are likely affected by the observed formation of conical domains, along with a varying width of the tissue phase at the column or domain boundaries.

\section{Acknowledgements}

This work was supported by the Knut and Alice Wallenberg's (KAW) Foundation through a Fellowship and Project Grant [KAW 2015.0043]; the Swedish Research Council [2016-04412 and 642-2013-8020]; the Swedish Government Strategic Research Area in Materials Science on Functional Materials at Linköping University [Faculty Grant SFO-Mat-LiU No. 2009 00971]; and the Research Infrastructure Fellow program [RIF 14-0074]. Financial support by the Swedish Research Council [International Career Grant No. 330-2014-6336], Marie 
Sklodowska Curie Actions COFUND [Project INCA 600398], and the Swedish Foundation for Strategic Research through the Future Research Leaders 6 program is gratefully acknowledged by BA. LH and POÅP acknowledge the KAW Foundation for support of the electron microscopy laboratory in Linköping.

\section{References}

[1] R.G. Munro, Material properties of titanium diboride, J. Res. Natl. Inst. Stan., 105 (2000) 709-720.

[2] M. Berger, L. Karlsson, M. Larsson, S. Hogmark, Low stress $\mathrm{TiB}_{2}$ coatings with improved tribological properties, Thin Solid Films, 401 (2001) 179-186.

[3] J. Chen, J.A. Barnard, Growth, structure and stress of sputtered $\mathrm{TiB}_{2}$ thin films, Mat. Sci. Eng. A, 191 (1995) 233-238.

[4] P.H. Mayrhofer, C. Mitterer, J.G. Wen, J.E. Greene, I. Petrov, Self-organized nanocolumnar structure in superhard TiB 2 thin films, Appl. Phys. Lett., 86 (2005) 131909. [5] T.F. Zhang, B. Gan, S. Park, Q.M. Wang, K.H. Kim, Influence of negative bias voltage and deposition temperature on microstructure and properties of superhard $\mathrm{TiB}_{2}$ coatings deposited by high power impulse magnetron sputtering, Surf. Coat. Tech., 253 (2014) 115122.

[6] F. Kunc, J. Musil, P.H. Mayrhofer, C. Mitterer, Low-stress superhard Ti-B films prepared by magnetron sputtering, Surf. Coat. Tech., 174-175 (2003) 744-753.

[7] M. Berger, K. Larsson, S. Hogmark, Evaluation of magnetron-sputtered $\mathrm{TiB}_{2}$ intended for tribological applications, Surf. Coat. Tech., 124 (2000) 253-261.

[8] N. Kalfagiannis, G. Volonakis, L. Tsetseris, S. Logothetidis, Excess of boron in $\mathrm{TiB}_{2}$ superhard thin films: A combined experimental and $a b$ initio study J. Phys. D Appl. Phys., 44 (2011) 385402.

[9] S. Ramalingam, L. Zheng, Film-substrate interface stresses and their role in the tribological performance of surface coatings, Tribol. Int., 28 (1995) 145-161.

[10] P.H. Mayrhofer, C. Mitterer, L. Hultman, H. Clemens, Microstructural design of hard coatings, Prog. Mater. Sci., 51 (2006) 1032-1114.

[11] S. PalDey, S.C. Deevi, Single layer and multilayer wear resistant coatings of (Ti,Al)N: A review, Mat. Sci. Eng. A, 342 (2003) 58-79.

[12] V. Moraes, H. Riedl, C. Fuger, P. Polcik, H. Bolvardi, D. Holec, P.H. Mayrhofer, Ab initio inspired design of ternary boride thin films, Sci. Rep., 8 (2018) 9288.

[13] V. Moraes, C. Fuger, V. Paneta, D. Primetzhofer, P. Polcik, H. Bolvardi, M. Arndt, H. Riedl, P.H. Mayrhofer, Substoichiometry and tantalum dependent thermal stability of $\alpha-$ structured W-Ta-B thin films, Scr. Mater., 155 (2018) 5-10.

[14] P.H. Mayrhofer, A. Hörling, L. Karlsson, J. Sjölen, T. Larsson, C. Mitterer, L. Hultman, Self-organized nanostructures in the Ti-Al-N system, Appl. Phys. Lett., 83 (2003) 2049-2051. [15] M.A. Monclus, M.A. Baker, C. Rebholz, V. Stolojan, P.N. Gibson, A. Leyland, A. Matthews, Nanostructural studies of PVD TiAlB coatings, Surf. Interface Anal., 38 (2006) 731-735.

[16] C. Rebholz, A. Leyland, J.M. Schneider, A.A. Voevodin, A. Matthews, Structure, hardness and mechanical properties of magnetron-sputtered titanium-aluminium boride films, Surf. Coat. Tech., 120-121 (1999) 412-417.

[17] B. Alling, H. Högberg, R. Armiento, J. Rosen, L. Hultman, A theoretical investigation of mixing thermodynamics, age-hardening potential, and electronic structure of ternary $\mathrm{M}^{11-}$ ${ }^{\mathrm{x}} \mathrm{M}^{2 \mathrm{x}} \mathrm{B}_{2}$ alloys with $\mathrm{AlB}_{2}$ type structure, Sci. Rep., 5 (2015) 9888. 
[18] A. Mockute, J. Palisaitis, B. Alling, P. Berastegui, E. Broitman, L.-Å. Näslund, N. Nedfors, J. Lu, J. Jensen, L. Hultman, J. Patscheider, U. Jansson, P.O.Å. Persson, J. Rosen, Age hardening in $\left(\mathrm{Ti}_{1-\mathrm{x}} \mathrm{Al}_{\mathrm{x}}\right) \mathrm{B}_{2+\Delta}$ thin films, Scr. Mater., 127 (2017) 122-126.

[19] W. Oliver, G. Pharr, Measurement of hardness and elastic modulus by instrumented indentation: Advances in understanding and refinements to methodology, J. Mater. Res., 19 (2004) 3-20.

[20] E. Broitman, Indentation hardness measurements at macro-, micro-, and nanoscale: A critical overview, Tribol. Lett., 65 (2017) 23.

[21] W. Oliver, G. Pharr, An improved technique for determining hardness and elastic modulus using load and displacement sensing indentation experiments, J. Mater. Res., 7 (1992) 1564-1583

[22] A. Gubbens, M. Barfels, C. Trevor, R. Twesten, P. Mooney, P. Thomas, N. Menon, B. Kraus, C. Mao, B. McGinn, The GIF Quantum, a next generation post-column imaging energy filter, Ultramicroscopy, 110 (2010) 962 - 970.

[23] $\mathrm{AlB}_{2}$ Crystal Structure: Datasheet from "PAULING FILE Multinaries Edition - 2012" in SpringerMaterials (https://materials.springer.com/isp/crystallographic/docs/sd_1140173), Springer-Verlag Berlin Heidelberg \& Material Phases Data System (MPDS), Switzerland \& National Institute for Materials Science (NIMS), Japan.

[24] E.J. Felten, The preparation of aluminium diboride, AlB2, J. Am. Ceram. Soc., 78 (1956) 5977-5978.

[25] I. Petrov, A. Hall, A. Mei, N. Nedfors, I. Zhirkov, J. Rosen, A. Reed, B. Howe, G. Greczynski, J. Birch, L. Hultman, J.E. Greene, Controlling the boron-to-titanium ratio in magnetron-sputter-deposited $\mathrm{TiB}_{\mathrm{x}}$ thin films J. Vac. Sci. Technol. A, 35 (2017) 050601. [26] J. Neidhardt, S. Mraz, J.M. Schneider, E. Strub, W. Bohne, B. Liedke, W. Möller, C. Mitterer, Experiment and simulation of the compositional evolution of Ti-B thin films deposited by sputtering of a compound target, J. Appl. Phys., 104 (2008) 063304.

[27] C. Mitterer, J. Komenda-Stallmaier, P. Losbichler, P. Schmölz, W.S.M. Werner, H. Störi, Sputter deposition of decorative boride coatings, Vacuum, 46 (1995) 1281-1294.

[28] P. Malinovskis, J. Palisaitis, P.O.Å. Persson, E. Lewin, U. Jansson, Synthesis and characterization of $\mathrm{MoB}_{2-\mathrm{x}}$ thin films grown by nonreactive DC magnetron sputtering, J. Vac. Sci. Technol. A, 34 (2016) 031511.

[29] F. Adibi, I. Petrov, L. Hultman, U. Wahlström, T. Shimizu, D. McIntyre, J.E. Greene, Defect structure and phase transitions in epitaxial metastable cubic $\operatorname{Ti}_{0.5} \mathrm{Al}_{0.5} \mathrm{~N}$ alloys grown on $\mathrm{MgO}(001)$ by ultra-high-vacuum magnetron sputter deposition, J. Appl. Phys., 69 (1991) 6437-6450.

[30] A. Flink, M. Beckers, J. Sjölen, T. Larsson, S. Braun, L. Karlsson, L. Hultman, The location and effects of $\mathrm{Si}$ in $\left(\mathrm{Ti}_{1-\mathrm{x}} \mathrm{Si}_{\mathrm{x}}\right) \mathrm{N}_{\mathrm{y}}$ thin films, J. Mater. Res., 24 (2009) 2483-2498. [31] J.E. Jakes, C.R. Frihart, J.F. Beecher, R.J. Moon, P.J. Resto, Z.H. Melgarejo, O.M. Suárez, H. Baumgart, A.A. Elmustafa, D.S. Stone, Nanoindentation near the edge, J. Mater. Res., 24 (2009) 1016-1031

[32] A.L. Ivanovskii, Hardness of hexagonal $\mathrm{AlB}_{2}$-like diborides of s, $\mathrm{p}$ and $\mathrm{d}$ metals from semi-empirical estimations, Int. J. Refract. Metals. Hard Mater., 36 (2013) 179-182.

[33] W.-G. Jiang, J.-J. Su, X.-Q. Feng, Effect of surface roughness on nanoindentation test of thin films, Eng. Fract. Mech., 75 (2008) 4965-4972. 


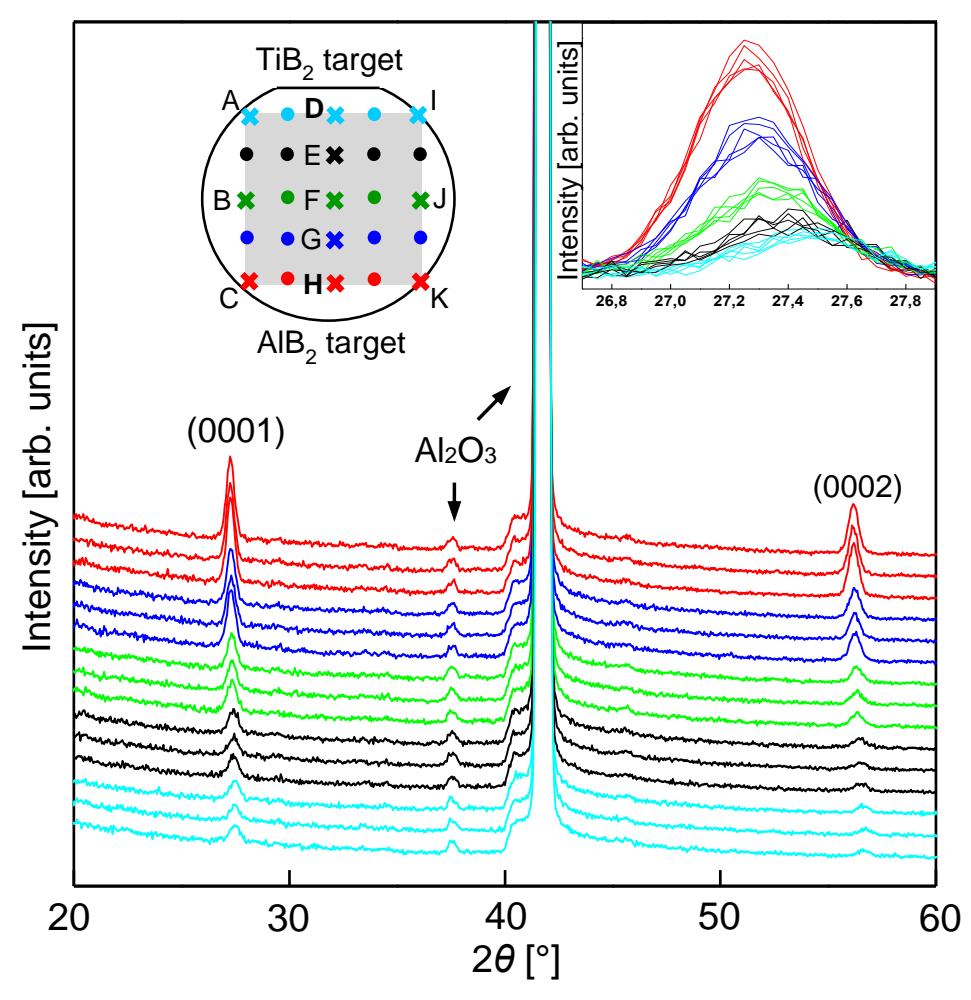



b) Al-L $=4$ c) B-K $1+4=4+4=$ mint

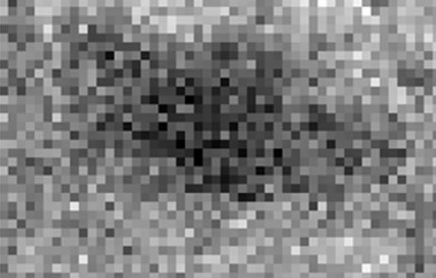
d) $\mathrm{Ti}-\mathrm{L}$

\section{e) O-K}
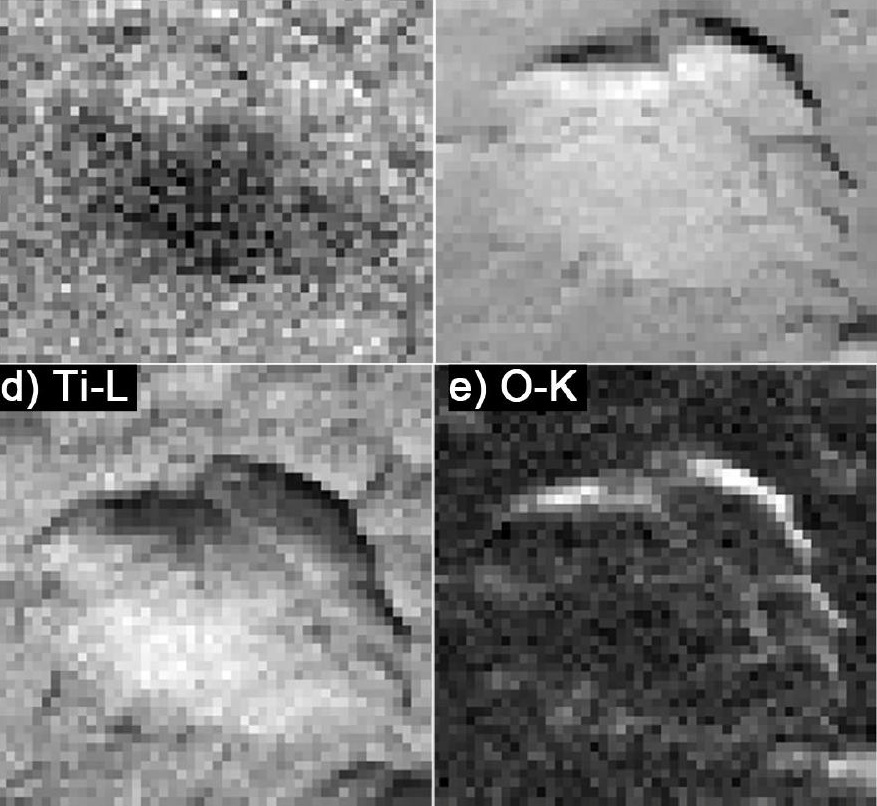


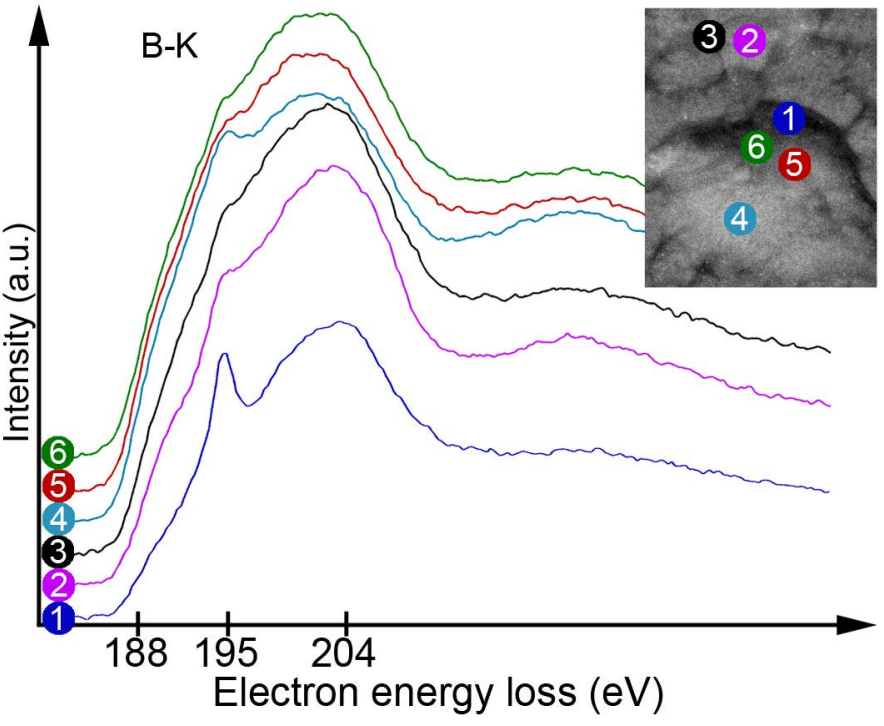



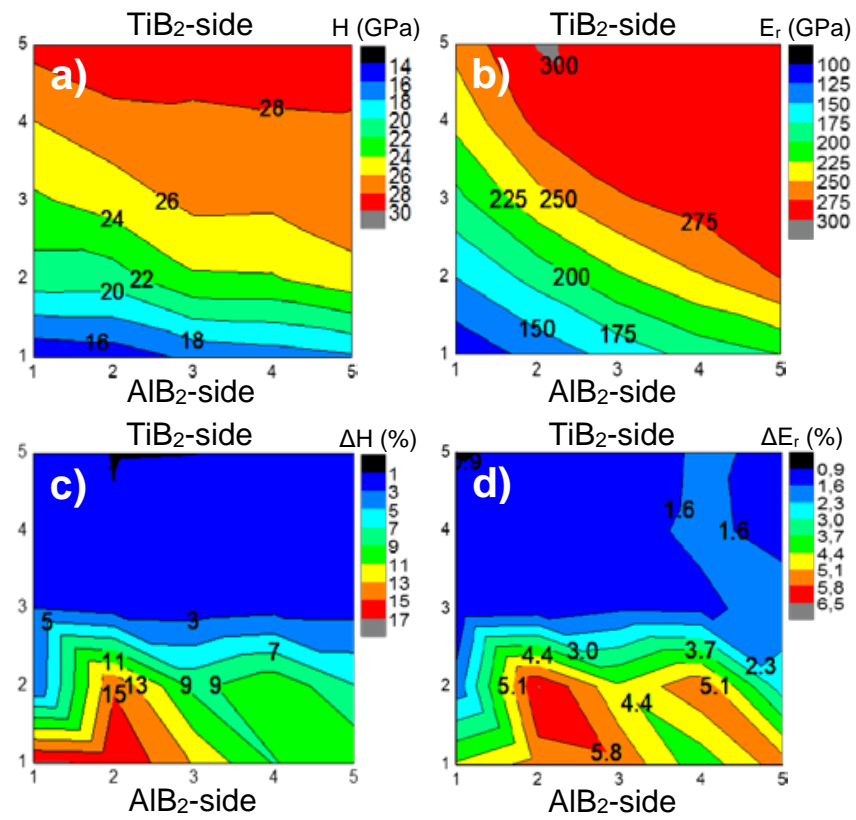


\begin{tabular}{|c|c|c|c|c|c|c|c|}
\hline & Ti & Al & B & $\mathbf{O}$ & C & $\mathbf{N}$ & \multirow{12}{*}{ 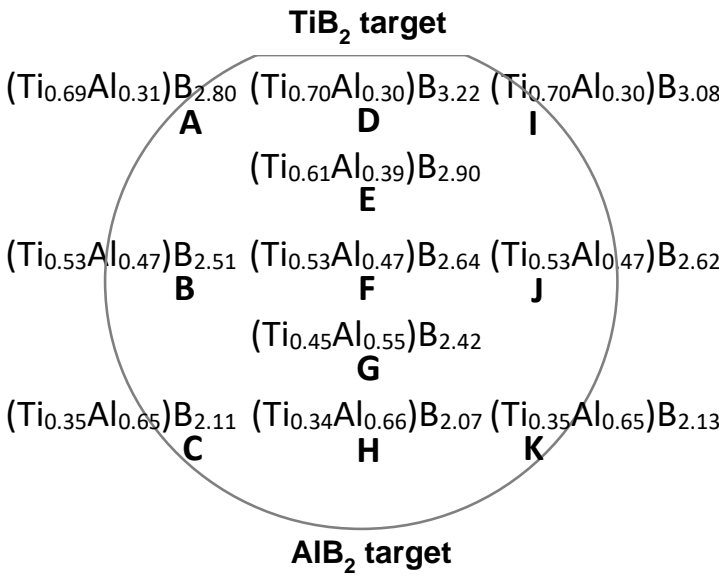 } \\
\hline A & 15.0 & 6.9 & 1.4 & 12.7 & 3.4 & 0.6 & \\
\hline B & 12.5 & 10.9 & 58.7 & 13.9 & 3.4 & 0.6 & \\
\hline $\mathrm{C}$ & 8.6 & 15.9 & 51.8 & 17.6 & 5.4 & 0.7 & \\
\hline D & 15.1 & 6.4 & 69.2 & 7.1 & 1.8 & 0.5 & \\
\hline $\mathbf{E}$ & 13.8 & 8.7 & 65.2 & 10.1 & 1.7 & 0.5 & \\
\hline $\mathbf{F}$ & 12.8 & 11.4 & 63.9 & 10.1 & 1.4 & 0.5 & \\
\hline G & 11.5 & 14.0 & 61.7 & 10.5 & 1.8 & 0.5 & \\
\hline $\mathbf{H}$ & 8.1 & 15.9 & 49.6 & 18.4 & 7.6 & 0.4 & \\
\hline I & 15.4 & 6.6 & 67.8 & 7.4 & 2.3 & 0.5 & \\
\hline $\mathbf{J}$ & 12.6 & 11.2 & 62.3 & 11.7 & 1.7 & 0.5 & \\
\hline$K$ & 8.9 & 16.4 & 53.8 & 16.7 & 3.7 & 0.5 & \\
\hline
\end{tabular}




\section{Table Captions}

Table 1 Elemental composition [at. \%] and corresponding stoichiometry determined by XPS at selected positions. The estimated error is \pm 0.5 at. $\%$.

\section{Figure Captions}

Fig. 1 XRD $\theta-2 \theta$ scans acquired as $5 \times 5$ array on the wafer showing peaks related to the $\mathrm{AlB}_{2}-$ type structure. The top-right inset shows the (0001) peak at higher magnification revealing higher $2 \theta$ angles and lower intensities for the $\mathrm{TiB}_{2}$-side of the wafer. The wafer orientation with respect to the targets along with the XRD and nanoindentation ( $\bullet$ and $\boldsymbol{x}), \operatorname{XPS}(\boldsymbol{x})$, and TEM (bold letters) analysis points are also shown.

Fig. 2 (a) Plan-view and (b) cross-sectional STEM-HAADF images together with corresponding electron diffraction patterns showing the microstructure of $\left(\mathrm{Ti}_{0.34} \mathrm{Al}_{0.66}\right) \mathrm{B}_{2.07}$ film (position H). Plan-view EDX maps displaying elemental (c) Ti, (d) Al, and (e) O distributions.

Fig. 3 (a) Plan-view STEM-HAADF images together with corresponding EELS maps displaying elemental (b) Al, (c) B, (d) Ti, and (e) O distributions.

Fig. 4 EELS B- $K$ edge spectra recorded from various regions in the plan-view from $\mathrm{Ti}_{0.34} \mathrm{Al}_{0.66} \mathrm{~B}_{2.07}$ film. (1): B tissue phase surrounding a conical defect and containing $\mathrm{O},(2)$ : grain in the film, (3): tissue in the film, (4): Ti-rich side of the conical defect, (5): Al-rich side of the conical defect, and (6): edge of the Al-rich side of the conical defect (B edge integrated intensity is the highest in this point (see Fig. 3c)).

Fig. 5 (a) Plan-view and (b) cross-sectional STEM-HAADF images together with corresponding electron diffraction patterns showing the microstructure of $\left(\mathrm{Ti}_{0.70} \mathrm{Al}_{0.30}\right) \mathrm{B}_{3.22}$ film (position D). Cross-sectional high-resolution STEM-HAADF images together with selective area electron diffraction patterns showing the lattice plane orientation in the $\left(\mathrm{Ti}_{0.70} \mathrm{Al}_{0.30}\right) \mathrm{B}_{3.22}$ film close to film-substrate interface (c) and near the film top surface (d).

Fig. 6 Nanoindentation maps of the variation in (a) hardness and (b) reduced elastic modulus across the Ti-Al-B coating deposited on an $\mathrm{Al}_{2} \mathrm{O}_{3}$ wafer; (c) and (d) visualize the data dispersion for the hardness and elastic modulus values, respectively, in each analyzed area. Larger data dispersion on $\mathrm{H}$ most likely originates from the formation of conical domains observed in TEM (see Fig. 2a and 3). The position of the $\mathrm{TiB}_{2}$ and $\mathrm{AlB}_{2}$ targets relative to the wafer during the deposition as well as the mapped area are indicated in the inset in Fig. 1. 